\title{
Differential Diagnosis of Secondary Center of Ossification Abnormalities
}

\author{
Tiffany Huynh ${ }^{1}$, Moheib Ahmed ${ }^{1}$ and Waleed Kishta ${ }^{2 *}$ \\ ${ }^{1}$ Department of Orthopaedic Surgery, University of Manitoba, Canada \\ ${ }^{2}$ Department of Orthopaedic Surgery, Western University, Canada
}

Submission: November 17, 2016; Published: November 28, 2016

*Corresponding author: Waleed Kishta, Department of Orthopaedic Surgery, Western University, 308-1420 Beaverbrook Ave, London, ON, Canada, N6H 5W5, Tel: 519-685-8021; Fax: 519-685-8038; Email: wkishta@yahoo.com

\begin{abstract}
Background: An abnormal secondary center of ossification (SCO) is a topic infrequently considered in orthopaedic literature but may result in significant morbidity and mortality in the pediatric patient. There exists a paucity of literature which may assist clinicians when assessing these uncommon pathologies.

Methods: Available literature was surveyed and the differential diagnosis of abnormal SCO was organized according to radiographic findings.

Results: This review article provides clinicians with an evidence-based quick-reference guide in approaching SCO pathologies. First, it discusses the basic anatomy and physiology of the pediatric skeleton. Secondly, it describes the basic types of irregular SCO on may encounter based on radiographic findings.

Conclusions: This discussion of SCO pathologies assists clinicians in approaching the differential diagnosis of an infrequently encountered, yet clinically significant, set of orthopaedic presentations.

Keywords: Pediatric; Orthopaedic; Secondary center of ossification; Epiphysis; Stippled epiphysis; Hypoplastic epiphysis; Dysplastic epiphysis; Hyperplastic epiphysis; Epiphysis necrosis; Precocious Epiphysis; Multiple epiphyses; Rickets; Osteomalacia; Chondroblastoma
\end{abstract}

\section{Introduction}

The anatomy of a child's bone may be divided into its basic components: the epiphysis, physis, metaphysis, and diaphysis. An appreciation of the growth and function of each structure is critical whenever a clinician encounters pathologies in the pediatric skeleton. The following review discusses the differential diagnoses of abnormal secondary centers of ossification (SCO), a topic which is infrequently considered in orthopaedic literature, but may result in significant morbidity and mortality in the pediatric patient. It provides the fundamental tools in approaching children with this condition in two ways: First, by surveying the basic anatomy and physiology of the pediatric skeleton. Second, by describing the basic types of irregular SCO one may encounter. The following discussion will assist clinicians in developing a practical approach towards the differential diagnoses of abnormal secondary centers of ossification.

\section{Anatomy and growth of the pediatric skeleton}

Primary centers of ossification: During week eight of embryological development, bone arises from osteoblasts in the primary centers of ossification (PCO). In all long bones, the diaphysis is the single primary center of ossification and forms the shaft of the bone. In contrast, vertebrae and flat bones consist of multiple PCO. As a child develops, the diaphysis undergoes appositional growth with layers of periosteal membranous osseous tissue deposited over the original enchondral model. The shaft enlarges circumferentially but does not lengthen longitudinally [1-3].

The Epiphysis and the secondary center of ossification: The epiphysis flanks each end of the long bone and rests upon the physis. A joint is formed when an epiphysis articulates with 
an adjacent epiphysis of the bone. The epiphyseal physis lies perpendicular to the axis of the long bone and is responsible for longitudinal growth. In newborns, almost all epiphyses are exclusively cartilaginous and accordingly, are not seen on radiographs $[4,5]$. Secondary centers of ossification often develop within the cartilaginous epiphysis, permitting the epiphysis to expand globally (i.e. all directions) by enchondral ossification.

However, the number and location vary with each bone. In most long bones, the epiphysis at each end contains a SCO but in some, such as the phalanges and clavicles, the SCO only forms at one end [6,7]. Sometimes, multiple epiphyseal ossification centers form, such as in the humerus, which contains two proximal and four distal SCO. In particular bones, one single cartilaginous epiphysis divides into two SCO, such as with the proximal tibial epiphysis and tibial tubercle apophysis [8].

The Apophysis: The apophysis is essential to bone motion and stability as it is the attachment site f $\quad 0 \quad r$ musculotendinous structures. Unlike the epiphysis, it does not usually articulate with adjacent bones and its physis lies parallel or oblique to the axis of the long bone, so it does not contribute to longitudinal growth. However, in flat bones, the apophyses participate in circumferential growth and in vertebrae, elongate the processes. The ends of particular bones function like an epiphysis and an apophysis. Specifically, the distal humerus, proximal ulna, proximal femur and proximal tibia are involved both in joint movement and musculotendinous attachment $[9,10]$.

The Metaphysis: The metaphysis is the flared end of the shaft that connects the diaphysis to the physis. Its spongy, trabecular center is encased in a thin layer of cortical bone.

The Physis: Often referred to as simply the physis, the primary physis rests between the epiphysis and metaphysis. There also exist epiphyseal and apophyseal physes. These physes share similar structures and function with its primary counterpart [2].

Blood supply: The primary physis is an avascular structure and is supported by branches from three blood supplies: epiphyseal arteries, metaphyseal arteries, and periosteal arteries from the zone of Ranvier [11]. Branches from epiphyseal vessels are essential for the longitudinal growth of long bones as these vessels primarily nourish the germinal, proliferating and columnar cell zones. Originating from the epiphyseal arteries in the SCO, epiphyseal vessels traverse through cartilaginous canals in the resting zone to terminate in the proliferative zone [12]. In the unossified epiphysis, these canals are oriented in a parallel, longitudinal pattern but after the SCO develops, the canals assume a radial pattern.

Branches from metaphyseal arteries have a less direct influence on bone growth. These branches derive from periosteal vessels that penetrate the metaphysis peripherally and combine with intermedullary blood. These vascular channels then traverse through the gaps left by dying cartilage cells in the zone of provisional calcification. The branches are responsible for feeding osteoprogenitor cells and thus, the metaphyseal branches are crucial to osteogenic and chrondrocytic cell differentiation. Periosteal blood also flows through branches in the zone of Ranvier to support chrondroblast differentiation. This specialized zone contributes to circumferential growth of the primary physis [1].

Growth: In long bones, growth occurs via enchondral ossification at the physes [5,13]. The primary physis is responsible for the majority of growth, contributing to $95 \%$ of the bone's length, while the secondary physis contributes the remaining 5\% [14]. Most activity is concentrated in the proliferative, columnar, and hypertrophic zones, where physeal chondrocytes steadily increase in volume [15]. Long bone length is positively related to final chondrocyte volume and therefore, the rate of bone growth is affected by changes in chondrocytic activity [13]. A similar process of chondrocyte enlargement occurs in the epiphysis, where a much smaller physis surrounds the SCO [16]. However, unlike cartilage in the primary physis, the epiphysis develops a superficial layer of cartilage that is incapable of ossification. This layer forms articular cartilage, a structure essential to normal joint movement.

Physeal closure: As children mature, bone growth eventually ends with closure of the physis. The various physes of the body close at different times depending on their locations, however the process is similar throughout. Initially, there is a decrease in the number of chondrocytes in the germinal and proliferating zones. There is also a decrease in the number of vacuolated cells in the zone of hypertrophy. The physis thins as cartilage is steadily replaced by bone while capillary tufts from the metaphysis grow towards the SCO. Eventually, all that is left of the physis is the epiphyseal scar, a thin transverse line which may be seen radiographically [17].

\section{Abnormalities of the secondary center of ossification}

Stippled center of ossification: A heterogenous group of skeletal dysplasias are characterized by calcific stippling of the epiphyses. Patterns and disease prognosis vary according to the type of dysplasia $[18,19]$. In the potentially lethal rhizomelic-type of chondrodysplasia puncta, calcifications are symmetrically distributed in the proximal humerus and femur [20]. Affected children who survive beyond infancy will experience resolution of physeal stippling; however, there will remain severe lifelong epiphyseal abnormalities [21]. In the Conradi-Hünermann type of chondrodysplasia puncta, there is an asymmetric distribution of calcific deposits at the ends of long bones, vertebral processes, carpal and tarsal bones, and ischiopubic bones. Upon resolution of the stippling, children have less severe epiphyseal changes than those with rhizomelic-type. Thus, assessment of the pattern 


\section{Orthopedics and Rheumatology Open Access Journal}

and distribution of epiphyseal stippling is crucial in evaluating the differential diagnoses and prognosis (Table 1).

Table 1: The differential diagnosis of stippled secondary centers of ossification includes the following conditions, each possessing their own unique radiographic findings [39].

\begin{tabular}{|c|c|}
\hline Condition & Radiographic findings \\
\hline $\begin{array}{l}\text { Chondrodysplasia punctata, } \\
\text { rhizomelic } \\
\text { type }\end{array}$ & $\begin{array}{l}\text { Punctate calcifications in the } \\
\text { proximal humerus and } \\
\text { femur } \\
\text { Symmetrical distribution } \\
\text { Absent stippling in the axial } \\
\text { skeleton } \\
\text { Severe epiphyseal changes after } \\
\text { stippling resolution }\end{array}$ \\
\hline $\begin{array}{l}\text { Chondrodysplasia punctata, } \\
\text { Conradi- } \\
\text { Hünermann }\end{array}$ & $\begin{array}{l}\text { Punctate calcifications at the ends } \\
\text { of the long bones, } \\
\text { processes of vertebrae, carpal and } \\
\text { tarsal } \\
\text { bones, and ischiopubic bones } \\
\text { Asymmetrical distribution } \\
\text { Less severe epiphyseal changes } \\
\text { after stippling } \\
\text { resolution }\end{array}$ \\
\hline Warfarin embryopathy & $\begin{array}{l}\text { Stippled calcifications in the } \\
\text { appendicular and axial } \\
\text { skeleton }\end{array}$ \\
\hline Zellweger syndrome & $\begin{array}{l}\text { Stippled calcifications of the hips } \\
\text { and patellas }\end{array}$ \\
\hline
\end{tabular}

Radiographic findings of stippled secondary centers of ossification.

Table 2: The differential diagnosis of hypoplastic, dysplastic, and dysgenetic secondary centers of ossification include the following conditions, each possessing their own unique radiographic findings [40].

\begin{tabular}{|c|c|}
\hline Condition & Radiographic findings \\
\hline Nail-patella syndrome & $\begin{array}{c}\text { Hypoplasia of capitellum and radial } \\
\text { head } \\
\text { distal humerus }\end{array}$ \\
Increased carrying angle of elbow \\
Hypoplastic absent patellas \\
Hypoplasia of the lateral portions of \\
the distal femoral \\
epiphyses
\end{tabular}

\begin{tabular}{|c|c|}
\hline Multiple epiphyseal dysplasia & $\begin{array}{l}\text { Irregular epiphyses (flat in Ribbing } \\
\text { type, small in Fairbank } \\
\text { type) } \\
\text { Mild shortening of tubular bones } \\
\text { Normal metaphyses } \\
\text { Early, progressive osteoarthritis }\end{array}$ \\
\hline Kniest dysplasia & $\begin{array}{c}\text { Irregular, late-appearing proximal } \\
\text { femoral epiphyses } \\
\text { In childhood, large and deformed } \\
\text { epiphyses } \\
\text { Short and broad femoral necks } \\
\text { Broad metaphyses } \\
\text { Short tubular bones }\end{array}$ \\
\hline Stickler syndrome & $\begin{array}{l}\text { In childhood, mild epiphyseal } \\
\text { dysplasia most prominent at } \\
\text { proximal femurs and distal tibias } \\
\text { Asymmetrical hypoplasia of distal } \\
\text { tibial epiphysis with } \\
\text { external slanting of the talar dome } \\
\text { In adulthood, secondary } \\
\text { degenerative arthropathy }\end{array}$ \\
\hline Chondroectodermal dysplasia & $\begin{array}{l}\text { Deficient ossification of the lateral } \\
\text { portions of proximal tibial } \\
\text { epiphysis and metaphysis } \\
\text { Downward slanting of the lateral } \\
\text { end of proximal tibias } \\
\text { Knock-knee deformity }\end{array}$ \\
\hline Parastremmatic dwarfism & $\begin{array}{c}\text { Coarse trabecular pattern ('flocky' } \\
\text { ossification) of the bone } \\
\text { structure of metaphyses and } \\
\text { epiphyses } \\
\text { Severe epiphyseal deformation }\end{array}$ \\
\hline Meyer dysplasia & $\begin{array}{l}\text { Late-appearing, small, irregular } \\
\text { femoral heads } \\
\text { Mild irregularities of proximal } \\
\text { femoral metaphyses } \\
\text { Spontaneous resolution of the } \\
\text { abnormalities, with formation } \\
\text { of normal femoral heads }\end{array}$ \\
\hline
\end{tabular}

Radiographic findings of hypoplastic, dysplastic and dysgenetic secondary centers of ossification

Hypoplastic, Dysplastic, Dysgenetic Centers of Ossification: An abnormal appearing epiphysis may be described as hypoplastic, dysplastic, and/or dysgenetic. Hypoplastic epiphyses are undersized or form later than normal. Dysplastic epiphyses appear irregular, and dysgenetic epiphyses result from defective development. The occurrence of such epiphyseal abnormalities may be explained by a number of causes (Table 2). Since epiphyseal ossification corresponds with skeletal 
growth, epiphyseal hypoplasia may be a normal physiologic indicator of delayed bone maturation. Asymmetrically sized epiphyses may also be normal in the growing child. However, in the context of an isolated hypoplastic epiphysis, the differential diagnosis includes trauma and infection [22]. Several systemic disorders may result in generalized epiphyseal hypoplasia, dysplasia and dysgenesis. Often, the primary defect is abnormal development of physeal cartilage and SCO. In some children, the number or arrangement of chondrocytes may be affected. In others, there may be excessive matrix formation or areas of matrix degeneration. These abnormalities result in delayed epiphyseal ossification and epiphyses that may appear flattened and fragmented [23].

Hyperplastic center of ossification: Children may present with large epiphyses, either localized to specific sites or generalized throughout the skeleton. In dysplasia epiphysealis hemimelica, or Trevor disease, affected epiphyses are enlarged due to cartilaginous overgrowth. Ittypically affects males, between the ages of 2-14 years old [24]. On radiographs, multiple foci of ossification may be visualized medial or lateral to the affected epiphysis. As its name suggests, there is hemimelic distribution of the abnormal growth with respect to the epiphysis, typically on the medial side. With time, an irregular epiphyseal bone mass forms, which leads to limb malalignment and precocious osteoarthritis. In infantile multisystem inflammatory disease, there is generalized distribution of enlarged epiphyses [25]. Affected children develop periostitis and osteoporosis. Given the significant long-term sequelae, it is essential to diagnose presentations of enlarged epiphyses (Table 3).

Table 3: The differential diagnosis of hyperplasic secondary centers of ossification includes the following conditions, each possessing their own unique radiographic findings [41].

\begin{tabular}{|c|c|}
\hline Condition & Radiographic findings \\
\hline Dysplasia epiphysealis hemimelica & $\begin{array}{l}\text { Multiple small foci of ossification adjacent to the } \\
\text { medial or lateral aspect of the affected epiphysis } \\
\text { coalescence with the epiphysis to form an irregular, } \\
\text { lobulated bone mass } \\
\text { Limb misalignment } \\
\text { Precocious osteoarthritis }\end{array}$ \\
\hline $\begin{array}{l}\text { Infantile multisystem inflammatory } \\
\text { disease }\end{array}$ & $\begin{array}{c}\text { Epiphyseal enlargement, irregularities, and } \\
\text { fragmentation } \\
\text { Metaphyseal widening } \\
\text { Periostitis } \\
\text { Osteoporosis }\end{array}$ \\
\hline $\begin{array}{c}\text { spondylo-megaepiphyseal - metaphyseal } \\
\text { dysplasia }\end{array}$ & $\begin{array}{c}\text { Large epiphyses } \\
\text { Metaphyseal irregularities } \\
\text { Defective vertebral body ossification }\end{array}$ \\
\hline
\end{tabular}

Radiographic findings of hyperplastic secondary centers of ossification

Aseptic Necrosis of the Secondary Center of Ossification: The epiphysis and its ossification center is sustained by a limited blood supply. This area is thus particularly vulnerable to ischemic necrosis when its vasculature is compromised. Most children present with isolated, unilateral involvement, although they may also be affected bilaterally or at multiple sites. The differential diagnoses may be divided into primary and secondary etiologies. An example of primary osteonecrosis is Legg-Calvè-Perthes disease, which affects the proximal femoral epiphysis in children. Secondary processes, such as Kienböck disease of the lunate, are precipitated by traumatic events [26]. Family history is relevant when assessing a child with osteonecrosis as some disorders suggest autosomal dominant inheritance, despite trauma often being a causative factor $[27,28]$.

Radiographically, the process of epiphyseal ischemic necrosis is similar among the different disorders, regardless of their pathogenesis and anatomic site. During the initial phase of cellular death, no radiographic changes are seen. Then, a radiolucent area surrounds the focus of necrosis and represents osteoporotic bone undergoing osteoclastic resorption. The necrotic area becomes radiodense as it develops a reactive interface with surrounding tissue. As the reactive interface remodels, the radiodense focus is bounded by a radiolucent edge, representing osteoclastic resorption of the interface. Meanwhile, the area surrounding the necrotic focus and reactive interface undergoes osteoblastic bone formation and appears relatively dense. Finally, the epiphysis becomes fragmented and the articular surface appears flattened as it collapses [29].

Precocious ossification and multiple ossification centers: Advanced bone maturation is a characteristic finding in several osteochondral dysplasias. Patients with Larsen syndrome, a primarily autosomal dominant disorder, experience ligamentous hyperlaxity and multiple joint dislocations. On ultrasonography, a capital femoral ossific nucleus may be found in children with 
Larsen syndrome as early as six days old, whereas unaffected children usually develop this site after three months old. On radiographs, advanced bone age and unique accessory SCO, such as in the calcaneus, are visible [30]. Children with Desbeqious dysplasia, an autosomal recessive disorder, also demonstrate precocious ossification, possibly years in advance of their peers. Unique SCO are often seen in radiographs of the metacarpals and phalanges. In summary, the presence of precocious ossification and accessory SCO may be suggestive of osteochondral dysplasias [31-33].

\section{Rickets and Osteomalacia}

There are more than 50 diagnoses in which either rickets or osteomalacia are prominent features [34]. However, there are significantly less diseases in which both are simultaneously present (Table 4). Rickets describes deficient mineralization of the physis, specifically at the zone of provisional calcification. Osteomalacia refers to inadequate calcium hydroxyapatite deposition on bone matrix [35]. Before complete ossification of the physis, both rickets and osteomalacia may coexist. Characteristic radiographic findings are seen in children with rickets, particularly in the physes of the tibia, distal femur, proximal humerus, distal radius, and distal ulna. There may be metaphyseal cupping and fraying, as well as bone rarefaction. The physis appears widened, irregular, and hypodense. In the context of osteomalacia, the appearance of rachitic growth plates may aid in narrowing the differential diagnoses.

Table 4: The differential diagnosis of rickets and osteomalacia include the following conditions, each possessing their own unique radiographic findings [42].

\begin{tabular}{|c|c|}
\hline Condition & Radiographic findings \\
\hline Rickets & $\begin{array}{l}\text { Widened, cupped, frayed metaphyses } \\
\text { Undermineralized metaphyses } \\
\text { Small, underossified epiphyses }\end{array}$ \\
\hline Hypophosphatasia tarda & $\begin{array}{l}\text { Rickets-like metaphyseal changes } \\
\text { Large unossified metaphyseal defects } \\
\text { Fragile, bowed long bones }\end{array}$ \\
\hline Vitamin A intoxication & $\begin{array}{c}\text { Cupped, splayed distal femoral } \\
\text { metaphyses } \\
\text { Cortial hyperostosis }\end{array}$ \\
\hline Achondroplasia & $\begin{array}{c}\text { Infancy: flaring and medial slanting of } \\
\text { distal femoral metaphysis } \\
\text { Childhood: inverted-V metaphyseal } \\
\text { appearance, medial metaphyseal } \\
\text { abnormalities }\end{array}$ \\
\hline Pseudoachondroplasia & $\begin{array}{l}\text { Irregular, widened, cupped metaphyses } \\
\text { Small, dysplastic epiphyses }\end{array}$ \\
\hline Metaphyseal acroscyphodyplasia & $\begin{array}{c}\text { Cupped metaphyses at the knee } \\
\text { Cone-shaped epiphyses } \\
\text { Deformed femoral condyles }\end{array}$ \\
\hline
\end{tabular}

\section{Radiographic findings of rickets and osteomalacia}

\section{Neoplastic and tumor-like lesions}

Chondroblastomas: Chondroblastomas are rare, benign tumors that predominantly affect the epiphysis or apophysis of long bones. These tumors comprise of less than $1 \%$ of primary bone tumors and $9 \%$ of benign bone tumors. Such growths are thought to develop from chondroblasts in the epiphyseal SCO, most commonly affecting the femur, humerus, and tibia. On radiographs, chondroblastomas appear as well-defined lucent lesions with central calcifications. Margins are smooth or lobulated, and the lesion is surrounded by a thin sclerotic rim (Figures 1-6). A third of patients demonstrate joint effusion [36]. Atypical features include extension of the tumor into the metaphysis or soft tissues [37-46]. When radiographs lack typical findings and appear nonspecific, chondroblastomas may be confused with other epiphyseal lesions (Table 5). 


\section{Orthopedics and Rheumatology Open Access Journal}
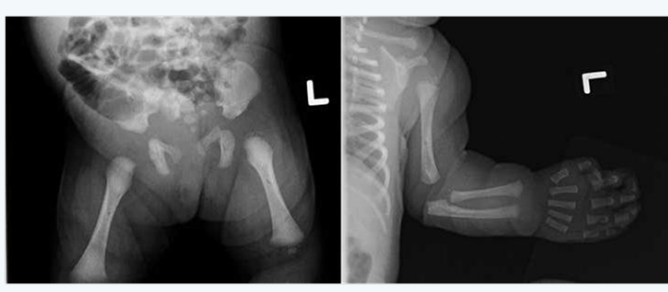

Figure 1: A-P radiographs of the pelvis and left upper extremity of a one month-old female with chondrodysplasic punctata. Stippled secondary centers of ossification of the left proximal femur and left proximal humerus are seen.

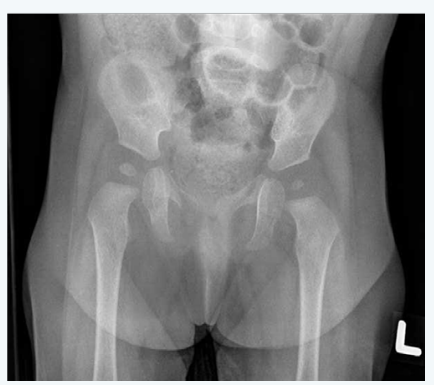

Figure 2: Nine month-old child with developmental dysplasia of the hip presenting with a hypoplastic center of ossification of the left proximal femur.

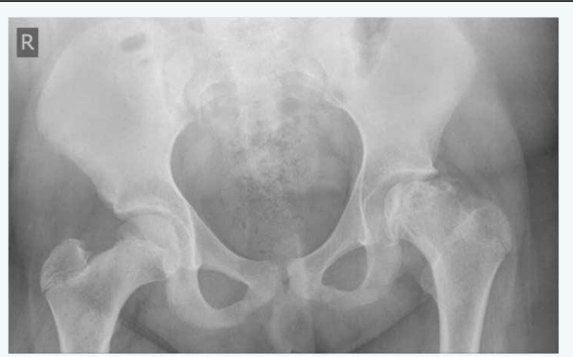

Figure 3: A-P radiograph of an eleven-year-old child with a hyplerplastic center of ossification of the left proximal femur.

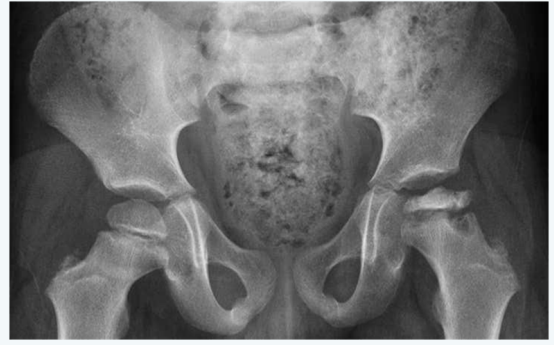

Figure 4: A-P radiograph of a seven-year-old child presenting with avascular necrosis of the center of ossification of the left proximal femur.

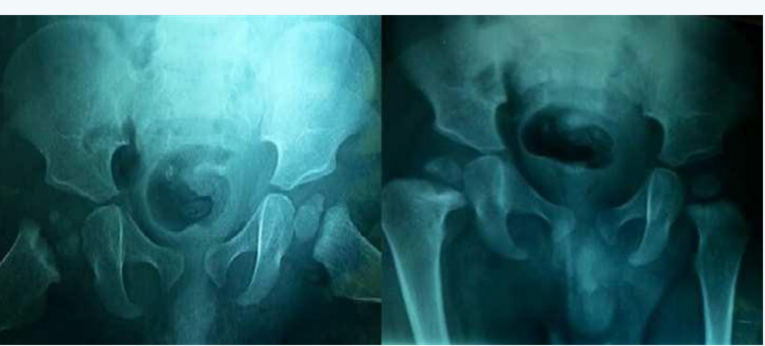

Figure 5: $\mathrm{AP}$ and frog-leg lateral pelvis radiographs showing multiple centers of ossification of the right proximal femur.

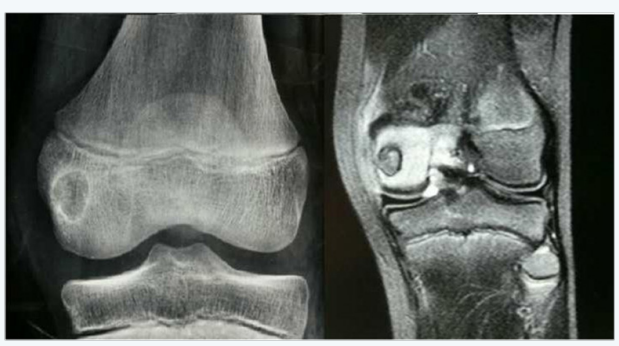

Figure 6: Radiograph and MRI of a twelve-year-old child with a chondoblastoma at the secondary center of ossification of the distal femur [38].

Table 5: The differential diagnosis of tumor-like epiphyseal lesions include the following conditions, each possessing their own unique radiographic findings.

\begin{tabular}{|c|c|}
\hline \multicolumn{1}{|c|}{ Condition } & Radiographic findings \\
\hline Clear cell chondrosarcoma [37] & Sclerotic rim surrounding slow-growing \\
\hline Dysplasia epiphysealis hemimelica [43] & Involves one side of epiphysis, \\
\hline & particularly at the distal tibia and distal \\
\hline & MRI most helpful due to cartilaginous \\
\hline Pseudocyst [44] & nature \\
\hline & Radiolucent lesion, often in proximal \\
\hline & humerus and calcaneus \\
\hline & Represents increased cancellous bone \\
\hline Bone abscess [45] & formation \\
\hline & Thick sclerotic rim, no central \\
\hline & calcifications \\
\hline & Serpentine, radiolucent tract extending to \\
\hline
\end{tabular}




\section{Orthopedics and Rheumatology Open Access Journal}

\begin{tabular}{|c|c|}
\hline & Rarely forms in epiphysis \\
\hline Giant cell tumor [46] & Rarely, sclerotic margin, no central \\
\hline & calcifications \\
\hline & Rarely in immature skeleton and \\
\hline & epiphysis \\
\hline
\end{tabular}

\section{Conclusion}

Secondary center of ossification abnormalities comprise an extensive assortment of complex and uncommon pathologies, which may initially be overwhelming for many clinicians. As highlighted in this review, irregular SCO may be divided into several types, based on shared and easily identifiable features. The radiographs included emphasize the unique features of each type, while the tables describe radiographic findings of possible diagnoses within each group. Knowledge provided within this review provides clinicians with an evidence-based quickreference guide to approaching a field of orthopaedics that is not often encountered; but may cause significant morbidity and mortality.

\section{References}

1. Barnewolt CE, Shapiro F, Jaramillo D (1997) Normal gadoliniumenhanced MR images of the developing appendicular skeleton: Part I. Cartilaginous epiphysis and physis. AJR Am J Roentgenol 169(1): 183189

2. Jaramillo D, Shapiro F (1998) Growth cartilage: normal appearance, variants and abnormalities. Magn Reson Imaging Clin N Am 6(3): 455471

3. Jaramillo D, Connolly SA, Mulkern RV, Shapiro F (1998) Developing epiphysis: MR imaging characteristics and histologic correlation in the newborn lamb. Radiology 207(3):637-645.

4. Jaramillo D, Hoffer FA (1992) Cartilaginous epiphysis and growth plate: normal and abnormal MR imaging findings. AJR Am J Roentgeno 158(5): 1105-1110.

5. Krauspe R, Raab P (1999) The role of growth plate (physis). J bone Joint Surg Br 81: 130-131.

6. R Wheeler Haines (1975) The histology of epiphyseal union in mammals. J Anat 120(Pt 1): 1-25

7. Roche AF (1965) The sites of elongation of human metacarpals and metatarsals. Acta Anat (Basel) 61(2): 193-202.

8. Peterson Helmet A (2007) Epiphyseal Growth Plate Fractures. Springer, New York, USA.

9. Ogden J (1988) Defining the growth plate. In: Behavior of the Growth Plate. Raven Press, 1-15.

10. Ogden JA (2000) Anatomy and physiology of skeletal development. In: Skeletal Injury in the Child. Springer, New York, USA, 1-37.

11. Trueta J, Morgan JD (1960) The vascular contribution to osteogenesis. I. Studies by the injection method. J Bone Joint Surg Br 42-B: 97-109.

12. Brighton CT (1984) The growth plate. Orthop Clin North Am 15(4): 571-595.

13. Hunziker E (1997) Growth plate formation, structure, and function. In: Skeletal Growth and Development: Clinical Issues and Basic Science Advances. Rosemon, IL: AAOS, 197-202.

14. J Dewey Bisgard, ME Bisgard (1935) Longitudinal growth of long bones. Arch Surg 31(4): 568-578.
15. Liow R, Urban J, Murray, DW (1999) Chondrocyte hypertrophy at the growth plate - the role of cell volume regulation in long bone growth. J Bone Joint Surg 51.

16. Buckwalter J, American Academy of Orthopaedic Surgeons, National Institutes of Health (1998) Skeletal growth and development: clinical issues and basic science advances. Amer Academy of Orthopaedic.

17. Brighton C (1974) Clinical problems in epiphyseal growth plate and development. In: Instruct Course Lect. 23: 105-122.

18. Swischuk LE, John SD (1995) Differential Diagnosis in Pediatric Radiology. ( $2^{\text {nd }}$ edn), Williams \& Wilkins, Baltimore, USA.

19. Theander G, Pettersson H (1978) Calcification in chondrodysplasia punctata. Relation to ossification and skeletal growth. Acta Radiol Diagn (Stockh) 19(1B): 205-222.

20. Mason RC, Kozlowski K (1973) Chondrodysplasia punctata. A report of 10 cases. Radiology 109(1): 145-150.

21. Wardinsky TD, Pagon RA, Powell BR, McGillivray B, Stephan M, et al. (2008) Rhizomelic chondrodysplasia punctata and survival beyond one year: a review of the literature and five case reports. Clin Genet 38(2): 84-93.

22. Kozlowski Kazimierz, Beighton Peter (2001) Gamut Index of Skeletal Dysplasias: An Aid to Radiodiagnosis. ( ${ }^{\text {rd }}$ edn), Springer, London, UK.

23. Shapiro F (1987) Epiphyseal disorders. N Engl J Med 317(27): 1702 1710.

24. Trevor D (1950) Tarso-epiphysial aclasis; a congenital error of epiphysial development. J Bone Joint Surg Br 32-B (2): 204-213.

25. Yarom A, Rennebohm RM, Levinson JE (1985) Infantile multisystem inflammatory disease: a specific syndrome? J Pediatr 106(3): 390-396.

26. Trueta J (1957) The normal vascular anatomy of the human femoral head during growth. J Bone Joint Surg Br 39-B (2): 358-394.

27. Douglas G, Rang M (1981) The role of trauma in the pathogenesis of the osteochondroses. Clin Orthop Relat Res 158: 28-32.

28. Fisher DE, Bickel WH (1971) Corticosteroid-induced avascular necrosis. A clinical study of seventy-seven patients. J Bone Joint Surg Am 53(5): 859-873.

29. Resnick D (1995) Osteonecrosis: pathogenesis. In: Diagnosis of Bone and Joint Disorders. ( $3^{\text {rd }}$ edn), Saunders, Philadelphia, USA, pp. 34583466.

30. Hara F, Kishikawa T, Tomishige H, Nishikawa O, Nishida Y, et al. (2000) A child with adrenocortical adenoma accompanied by congenital hemihypertrophy: report of a case. Surg Today 30(9): 861-865.

31. Al Kaissi A, Radler C, Klaushofer K, Grill F (2009) Advanced ossification of the carpal bones, and monkey wrench appearance of the femora, features suggestive of a propable mild form of desbeqious dysplasia: a case report and review of the literature. Cases J 2(1): 45.

32. Beemer FA, Kramer PPG, van der Harten HJ, Gerards LJ, Fraser FC, et al. (1985) A new syndrome of dwarfism, neonatal death, narrow chest, spondylometaphyseal abnormalities, and advanced bone age. Am J Med Genet 20(3): 555-558.

33. De la Rocha A, Birch JG, Schiller JR (2012) Precocious appearance of the capital femoral ossific nucleus in Larsen syndrome. J Bone Joint Surg Am 94(9): e55. 
34. Pitt MJ (1981) Rachitic and osteomalacic syndromes. Radiol Clin North Am 19(4): 581-599.

35. Mankin HJ (1974) Rickets, osteomalacia, and renal osteodystrophy. Part II. J Bone Joint Surg Am 56(2): 352-386.

36. Erickson JK, Rosenthal DI, Zaleske DJ, Gebhardt MC, Cates JM (2001) Primary treatment of chondroblastoma with percutaneous radiofrequency heat ablation: report of three cases. Radiology 221(2): 463468.

37. Giudici MA, Moser RP, Kransdorf MJ (1993) Cartilaginous bone tumors. Radiol Clin North Am 31(2): 237-259.

38. Ahmed M (2016) Chondroblastoma at the distal femoral epiphysis: interview with Dr. Moheib Ahmed, Lecturer of Orthopaedic Surgery at Mansoura University, Egypt.

39. Castriota-Scanderbeg Alessandro, Dallapiccola Bruno (2005) Abnormal Skeletal Phenotypes: From Simple Signs to Complex Diagnoses. Springer, Berlin, Germany.

40. Unger SL, Briggs MD, Holden P, Zabel B, Ala-Kokko L, et al. (2001) Multiple epiphyseal dysplasia: radiographic abnormalities correlated with genotype. Pediatr Radiol 31(1): 10-18.
41. Schlesinger AE, Poznanski AK, Pudlowski RM, Millar EA (1986) Distal femoral epiphysis: normal standards for thickness and application to bone dysplasias. Radiology 159(2): 515-519.

42. Bellini F, Chiumello G, Rimoldi R, Weber G (1984) Wedge-shaped epiphyses of the knees in two siblings: a new recessive rare dysplasia? Helv Paediatr Acta 39(4): 365-372.

43. Kuo RS, Bellemore MC, Monsell FP, Frawley K, Kozlowski K (1998) Dysplasia epiphysealis hemimelica: clinical features and management. J Pediatr Orthop 18(4): 543-548.

44. Resnick D, Cone RO (1984) The nature of humeral pseudocysts. Radiology 150(1): 27-28.

45. Azouz EM, Greenspan A, Marton D (1993) CT evaluation of primary epiphyseal bone abscesses. Skeletal Radiol 22(1): 17-23.

46. Schütte HE, Taconis WK (1993) Giant cell tumor in children and adolescents. Skeletal Radiol 22(3): 173-176.

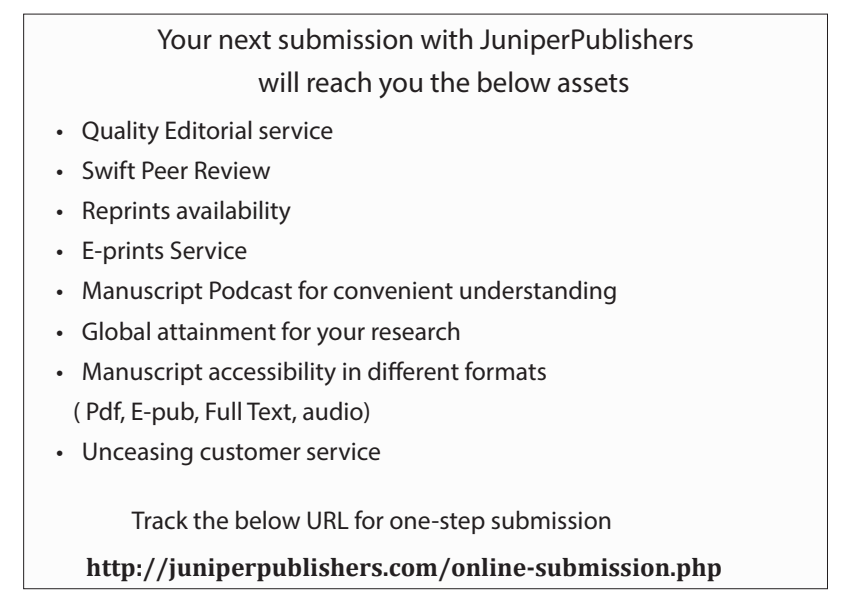

